1 Selwvn S. Skin preparation, the surgical "scrub" and related rituals. In: Karran S, ed. Controcersies in surgical sepsis. Eastbourne and New York: Praeger, 1980:23-32.

Selwrin S. Aseptic rituals unmasked. Br. Med f 1984:289:1642-3.

3 Lidwell OM. Lowbury EJL, Whyte W. Blowers R, Stanley SJ. Lowe D. Airborne contamination of wounds in joint replacement operations: the relationship to sepsis rates. 7 Hosp Infect

4 Lidwell OM. Lowbury EJL. Whyte W', Blowers R, Stanley SJ, Lowe D. The effect of ultraclean air in operating rooms on deep sepsis in the joint after total hip or knee replacement: a randomised tudv. Br. Med 7 1982;285:10-4

Medical Research Council. Design and ventilation of operating-room suites for control of infection and comfort. Lancel 1962;i1:945-51

6 Lidwell OM. Bacteriological considerations. In: Johnston DA. Hunter AR. eds. The design and utlization of operating theatres. London: Arnold, 1984:22-38.

Dondero TJ Jr. Rendtorff RC. Mallison GF, et al. An outbreak of legionnaires' disease associated with contaminated air-conditioning cooling tower. . V Engl f. Med 1980;302:365-70.

8 Howorth FH. The air in the operating theatre. In: Johnston DA, Hunter AR. eds. The design and utlization of operating theatres. London: Arnold, 1984:39-60.

9 Clark RP. Reed PJ. Seal DV. Stephenson ML. Ventilation conditions and airborne hacteria particles in operating theatres: proposed safe economies. f Hvg Camb, 1985:95:325-35.

\section{What price academic general practice?}

One of the most important changes I have seen in undergraduate medical education has been the development of teaching of general practice. Less than 30 years ago the University of Edinburgh created the first independent department of general practice; today there are 24 such departments in our undergraduate schools. The Mackenzie report on academic general practice (an edited version of which is published on $\mathrm{p}$ 1567) shows how these departments vary greatly in size and form. It looks at the strengths and weaknesses of the various systems and makes recommendations that will inevitably need resources if they are to be implemented. This thoughtful review deserves an equally thoughtful response.

Students should be given the opportunity of seeing for themselves how general practice works and what a general practitioner does. This applies to all branches of medicine, but the fact that half or more graduates now enter general practice makes this exposure particularly important. Teaching in general practice gives the student a chance to see those minor but important disorders that do not reach the teaching hospital and to realise that the episode that brings the patient into hospital has a beginning and an end, both of which are the responsibility of the general practitioner. One of the most important qualities of a good general practitioner is the ability to identify those patients who need referral to hospital-for an outpatient opinion or urgent admission. Students are unlikely to gain this insight through a few weeks or even a few months of attachment to a general practice, but they should at least learn the importance of this initial sifting process.

They might also learn something about the consequences of being admitted to hospital-who cares for the elderly spouse, safeguards the house and possessions, or feeds the cat? The follow up of patients discharged from hospital is equally important. What effect has the illness had on the patient or the family? What changes should be advised in the patient's way of life? At what point can the patient return to work? These aspects of illness cannot easily be taught in hospital because they depend so much on local domestic factors and the personality of the patient.

Teaching within general practice is thus essential, but how best to provide it? There can be no certain answer because (as with almost all medical teaching) no study has satisfactorily compared the impact of different educational systems on student knowledge or attitudes. Nor, because of the difficulty of measuring outcome, are such studies ever likely to take place. The approach has to be empirical, which provides fertile ground for bias and preference for those with the most powerful personalities_a not unfamiliar pattern within our teaching establishments.

My own preferences (or prejudices) have crystallised over the years. While I accept the usefulness of general practitioners contributing to the introductory clinical course, I believe that the bulk of this teaching should be carried out by a department of medicine. In this phase students need to spend as much time as possible at the bedside and with individual patients. Only when they have gone repeatedly through history taking and physical examination, preferably spending hours with each patient and even more hours reading and reflecting about their findings, should they be exposed to the short cuts that we all learn to take. The "physicianly approach" is best suited for their introductory needs, and I doubt if general practice can meet this requirement.

I agree with the Mackenzie report's advocacy of one to one teaching. Clinical medicine is best learnt through apprenticeship, and general practice offers an ideal opportunity for this. I am less happy with the report's proposal that all patient presentations should be planned in advance. This selectivity would introduce artificiality, and students are likely to learn more, I believe, with fewer set piece presentations and more exposure to "real life." I confess, too, that I have come to regard examinations as unreliable and unnecessary-except for the cynical, if pragmatic, device of failing a few students pour encourager les autres. Single student attachments to a practice should permit assessments to be made of their ability, attitudes, and knowledge, and I would like to see the examining process end there. General practice should not follow the rest of medicine in its belief that you have to examine students if you want their attendance and attention .

I was disappointed that the report did not give more consideration to multidisciplinary exposure during the three years of vocational training. There is no branch of medicine that fails to provide educationally valuable experience, and I strongly support the Short report's recommendation for widening the range of training during the early postgraduate phase.

The emphasis given by the report to clinical and operational research was pleasing. The opportunities for both are immense, but a one year training in research will not be sufficient. This may be enough for those who wish to dabble in research, but there should be a small cadre of "professionally" trained research workers capable of exploiting fully the opportunities offered in practice and they will need at least three years' training. A three year clinical research training, like those supported by the Medical Research Council, could be offered to general practitioners as well as hospital researchers.

The report is disappointingly silent on preventive medicine. Prevention requires changes in attitudes and living habits, and, although this was not the brief of the report, an emphatic statement of the crucial role of general practitioners in prevention might have helped to attract more sympathy for their needs - and, perhaps, more money.

The final section of the report deals with finance, and this, I am afraid, is where many of its proposals sink. Universities and hospitals are under great pressure, and a shift of resources is improbable; nor, I suspect, is there much chance of "new money" being found. Yet additional funding for general practice is needed. The subject is now established as a univerșity discipline, its teachers form a valued part of the undergraduate faculty, and most of the research carried out 
by the academic units deals with topics of the utmost importance and is carried out to the highest academic standards. The units deserve better funding.

RAYMOND HOFFENBERG

President,

Royal College of Physicians,

London NW1 4LE

\section{Severity scoring in intensive} care

Intensive care is demanding in both human and financial terms. Ethical considerations, common sense, and economic concerns all require that expensive resources should be concentrated on patients with potentially recoverable disease and not squandered on those with a manifestly hopeless prognosis—or used unnecessarily to "monitor" patients who are no more than at risk of developing a critical, life threatening illness. ${ }^{12}$ These categories are difficult to define precisely, and there is an understandable reluctance to withhold or-more difficult-withdraw treatment when there seems the slightest chance of ultimate recovery. The temptation to strive for survival at all costs is difficult to resist, even when there is no precedent for recovery, ${ }^{3}$ and unproved, extravagant remedies are likely to be tried as a last resort.

Clinicians faced with these difficult decisions may be helped by guidelines based on careful analysis of results achieved in comparable groups treated by different meansan approach as valid for intensive care as for other disciplines. Accurate comparisons are difficult, however, because multisystem disease and rapid change are common.

Various methods of prediction have been devised to deal with these difficulties. Some are applicable only to specific conditions, ${ }^{4-7}$ while others require the collection of very detailed information. ${ }^{8}$ One of the most widely used is the Glasgow coma scale, calculated from simple variables determined by clinical examination. ${ }^{9}$ Prognostic information has been derived from a data bank of more than 1000 patients with head injury by relating the severity of the initial insult to subsequent outcome, ${ }^{10}$ and this information has then been used to compare the results of different forms of treatment. ${ }^{11}$ Similar methods were used by Levy et al to predict outcome from non-traumatic coma ${ }^{12}$ and, more recently, to suggest individual prognosis after cardiac arrest. ${ }^{13}$

Specific scoring systems provide a means for comparing results and ensuring consistent standards, ${ }^{14}$ but they are applicable to only a few patients. A more general indication of severity of illness and consumption of resources is given by the therapeutic intervention scoring system, which is calculated from the frequency with which certain procedures and treatments are performed for each patient ${ }^{15}{ }^{16}$; but its value is diminished by differences in medical practice among centres and within one centre with time.

Knaus and his colleagues suggested that the severity of acute disease could be assessed by measuring the degree of abnormality of several physiological variables. ${ }^{17}$ They defined an acute physiology score derived from points scored for the extent of abnormality of 34 variables, and combined it with a rating for age and chronic health to formulate the acute physiology and chronic health evaluation (APACHE I) classification. Higher scores, indicating greater severity of illness, were associated with an increased mortality in hospital. The complexity of calculating the acute physiology score prompted simplifications, ${ }^{18}{ }^{19}$ most notably by Knaus $e t$ $a l$, who used the 12 most important and commonly recorded variables to create a shortened scoring system, APACHE II. Application of APACHE II to nearly 6000 patients in 13 American intensive care units showed its reliability for stratifying the degree of risk of subsequent death from a wide range of disorders. ${ }^{20}$ Similar physiological criteria have been used to define acute organ system failure and, by recording serial data, to relate prognosis to the number of systems affected and the duration of failure of each. ${ }^{21}$

The APACHE score is an index of risk on a population basis. Though it may contribute to decision making, ${ }^{22}$ it cannot be expected to provide an accurate individual prognosis. The importance of any physiological derangement is influenced by the nature of the underlying condition, and the APACHE score must be weighted by an appropriate factor before disease specific mortality predictions can be even contemplated. Acquisition of a large data bank is necessary for the assessment of specific risk, particularly for disorders which are rare or associated with a low mortality.

The APACHE scoring system is a powerful tool for clinical audit ${ }^{23}$ and for comparing different policies and treatment regimens. ${ }^{24}$ The decision by the Intensive Care Society to promote its use in the United Kingdom should be welcomed as a means of improving standards, rationalising the use of an expensive commodity, and ensuring that management is appropriate to individual needs and wishes.

C J MORGAN Doverdale fellow

M A BRanthwaIte

Doverdale Intensive Care Unit,

Brompton Hospital,

London SW'3 6HP

Anonymous. Intensive care audit [Editorial]. Lancet 1985;i:1428-9.

Jennett B. Inappropriate use of intensive care. Br Med J 1984;289:1709-11.

Schuster DP, Marion JM. Precedents for meaningful recovery during treatment in a medical intensive care unit: outcome in patients with hematologic malignancy. Am f Med 1983;75: 402-6.

4 Champion HR, Sacco WJ, Carnazzo AJ, Copes W, Fouty WJ. Trauma score. Crit Care Med $1981 ; 9: 672-6$.

Baker SP, O'Neil B, Haddum W, Long WB. The injury severity score: a method for describing patients with multiple injuries and evaluating emergency care. $\mathcal{F}$ Trauma 1974;14:187-96.

6 Elebute EA, Stoner HB. The grading of sepsis. Br f Surg 1983;70:29-31.

7 Feller I, Crane KH. National burn information exchange. Med Clin North Am 1970;50:1425-36.

8 Bland RD, Shoemaker WC, Abraham E, Cobo JC. Hemodynamic and oxygen transport patterns in surviving and nonsurviving postoperative patients. Crit Care Med 1985;13:85-90.

9 Teasdale G, Jennett B. Assessment of coma and impaired consciousness. A practical scale. Lancet 1974; ii: $81-4$.

10 Jennett B, Teasdale G, Braakman R, Minderhoud J, Heiden J, Kurze T. Prognosis of patients with severe head injury. Neurosurgery 1979;4:283-9.

11 Jennett B, Teasdale G, Fry J, et al. Treatment for severe head injury. I Neurol Neurosurg Psychiatry 1980;43:289-95.

12 Levy DE, Bates D, Caronna JJ, et al. Prognosis in non-traumatic coma. Ann Intern Med 1981;94:293-301.

13 Levy DE, Caronna JJ, Singer BH, Lapinski RH, Frydman H, Plum F. Predicting outcome from hypoxic-ischemic coma. FAMA 1985;253:1420-6.

4 Watt I, Ledingham IMcA. Mortality amongst multiple trauma patients admitted to an intensive therapy unit. Anaesthesia 1984;39:973-81.

15 Cullen DJ, Civetta JM, Briggs BA, Ferrara LC. Therapeutic intervention scoring system: a method for quantitative comparison of patient care. Crit Care Med 1974;2:57-60.

16 Keene AR, Cullen DJ. Therapeutic intervention scoring system: update. Crit Care Med 1983;11:1-3.

17 Knaus WA, Zimmerman JE, Wagner DP, Draper EA, Lawrence D. APACHE-acute physiology and chronic health evaluation: a physiologically based classification system. Crit physiology and chronic
Care Med 1981;9:591-7.

18 Le Gall JR, Loirat P, Alperovitch A, et al. A simplified acute physiology score for ICU patients. Crit Care Med 1984;12:975-7.

19 Bion JF, Edlin SA, Ramsay G, McCabe S, Ledingham IMcA. Validation of a prognostic score in critically ill patients undergoing transport. Br Med $\mathcal{F} 1985 ; 291: 432-4$.

20 Knaus WA, Draper EA, Wagner DP, Zimmerman JE. Apache II: a severity of disease classification system. Crit Care Med 1985;13:818-29.

21 Knaus WA, Draper EA, Wagner DP, Zimmerman JE. Prognosis in acute organ-system failure. Ann Surg 1985;202:685-93.

22 Zimmerman JE, Knaus WA, Sharpe SM, et al. The use and implications of "do not resuscitate" orders in intensive care units. FAMA 1986;255:351-6.

23 Knaus WA, Draper EA, Wagner DP, Zimmerman JE. Evaluation of outcome from intensive care in major medical centers. Ann Intern Med (in press).

24 Knaus WA, Wagner DP, Loirat $P$, et al. A comparison of intensive care in the USA and France. Lancet 1983;ii:642-6. 